\title{
A changing world
}

\begin{abstract}
A s Mr Robert B Kalina noted on page 515, this is the final issue of The Canadian Journal of Cardiology (CJC) to be published by Pulsus Group. As noted by Mr Kalina, this is a rather sad day for himself and the Pulsus staff, who have been publishing the CJC since 1985. Starting in January 2011, the CJC will be published by Elsevier under the direct ownership of the Canadian Cardiovascular Society (CCS). These new ownership and publishing agreements also largely coincide with the appointment of Dr Stanley Nattel as the third Editor-in-Chief of the CJC.

Change - such as this - can be uncomfortable for all concerned. However, I think that this is both a natural and a good evolution for the CJC. In 1985, I, and many others, did not foresee the need for, and therefore the future success of, the CJC. Indeed, when Mr Kalina and Dr Robert Beamish first approached the CCS to adopt the CJC as its official journal, I was one of the outspoken critics on the Council at the time. However, despite our rejection, the CJC did attract papers and publish regular issues on time. The result was that the CJC was accepted by the indexing services, which is an essential but nontrivial issue for any new journal. By 1990, two things became clear. First, the CJC was a 'successful' Canadian journal. Second, our international colleagues assumed that it was the journal of the CCS. As President of the CCS at that time, I was charged to enter into negotiations with Mr Kalina (they were not easy) to develop the relationship that has existed since that time. Needless to say, I think Mr Kalina was 'disturbed' when my name was proposed by the CCS as the individual to follow Dr Beamish as Editor-in-Chief in 1997. I served for 13.5 years as the editor of the CJC and, during this time, I learned to appreciate and respect Mr Kalina and his team at Pulsus. Although we have enjoyed many successes, the business model employed by Pulsus limited our potential for growing the influence of the journal - particularly in recent years when advertising revenues became more restricted. However, the support of Pulsus was always there for initiatives to improve the content or impact of the CJC, even when not consistent
\end{abstract}

with the best business practice. Clearly, Mr Kalina and the staff at Pulsus valued the CJC and the relationships with the cardiovascular community. I certainly have valued my relationship with them.

Meanwhile, the CCS was also evolving. Although the CJC was viewed for a long time as nice to have, it was not always seen as a critically important vehicle for the CCS and its membership. However, that has changed over recent years. Surveys have repeatedly indicated that (next to the Congress), the Journal was perceived to be the most important value of membership in the Society. After much discussion, it became clear to the Council that direct ownership of the CJC was needed if the Journal was to move to the next stage of development, particularly as a Canadian journal with a major international subscription base, readership and source of articles. Fortunately, the pieces all came together during 2010 when the CCS and Pulsus came to an agreement pertaining to how the sale could occur.

Is this good for the CJC? Absolutely. I cannot imagine how difficult it would have been if Mr Kalina decided not to sell and the CCS decided to establish a new journal. From the viewpoint of the cardiovascular community in Canada, it would have taken a long time for a new CCS journal to become indexed and achieve the name recognition of the CJC. I believe that the new arrangements will allow the CJC to seamlessly expand its influence internationally, grow in importance nationally and increase its impact as a cardiovascular journal.

I am proud to have been the Editor-in-Chief of the CJC during a period of growth, perhaps equivalent to adolescence. It will now be a pleasure to watch it move into the maturity of adulthood. I think we all owe a large thank you to Mr Kalina and the staff at Pulsus for the success of the past. We should also appreciate the vision and the willingness to assume risk on the part of the leadership at the CCS.

It is a time of change for the $\mathrm{CJC}$, but this feels right. Congratulations to all and best wishes for the future.

Eldon $R$ Smith OC MD FRCPC Editor-in-Chief Emeritus

\section{LETTER FROM THE PRESIDENT}

\section{The Canadian Cardiovascular Society thanks Pulsus Group}

\begin{abstract}
In this final issue of The Canadian Journal of Cardiology to be published by Pulsus Group, we wish to thank Robert B Kalina and his staff for their commitment to and passion for the Journal during our partnership of more than 20 years.

Pulsus Group has published the Journal for more than 26 years and it was with sincere gratitude that we showed our appreciation for Pulsus at the Canadian Cardiovascular Congress 2010 Awards Ceremony. Robert B Kalina, as owner of Pulsus Group and founder of The Canadian Journal of Cardiology, accepted recognition for his organization's significant contribution to cardiovascular research and knowledge dissemination in Canada.
\end{abstract}

The Canadian Cardiovascular Society (CCS) is pleased to assume ownership of The Canadian Journal of Cardiology from Pulsus Group. We look forward to the continued growth and impact of The Canadian Journal of Cardiology. In January 2011, the CCS will work with Elsevier to take the journal to the international stage. This is the next step for the CCS-owned journal, and will provide a global platform for excellent Canadian-generated and international research and knowledge, under the editorial leadership of Dr Stanley Nattel, based at the Montreal Heart Institute, Montreal, Quebec.

Blair J O'Neill, CCS President, on behalf of the CCS Membership 